\title{
Conectando saberes e 'superpoderes' para mediar tópicos em genética e saúde no ensino médio
}

\section{Connecting knowledge and 'superpowers' for mediar topics in genetics and health at high school}

\author{
${ }^{1}$ Juliana Macedo Nascimento \\ ${ }^{2}$ Rosane Moreira Meirelles
}

\section{RESUMO}

O conceito de genoma perpassa a compreensão da origem da vida e da biodiversidade frente às incríveis biotecnologias atuais. No entanto, pesquisas sobre o ensino de genética têm mostrado que estudantes do Ensino Médio não compreendem esse conceito tão pouco o relacionam com conteúdos do currículo obrigatório. Paralelamente, estudantes apresentam ideias distorcidas sobre a funcionalidade do material genético relacionando, sempre que possível, a personagens da ficção, como perfis extraordinários e sobrenaturais; o que torna ainda maior a distância entre os saberes da tríade escolar-popular-científico sobre esse tema. Pela potencialidade para discussões que o conceito de genoma apresenta no ensino de Biologia, este artigo apresenta e propõe uma estratégia didática com o uso de filmes do gênero superaventura aliando o conceito de genoma a tópicos de saúde no Ensino Médio. Para esta investigação, foram realizadas oficinas dialógicas com 115 alunos de quatro escolas públicas localizadas em áreas carentes do Estado do Rio de Janeiro, utilizando filmes de super-heróis da Marvel Comics. As concepções pré e pós-oficinas didáticas foram analisadas à luz da Teoria da Aprendizagem Significativa e revelaram a pertinência da atividade no que diz respeito à aproximação de saberes afins ao conceito de genoma e a relevância do tema perante o currículo escolar obrigatório.

Palavras-chave: ensino de genética; saúde; filmes de super-heróis; ensino médio.

\begin{abstract}
The concept of genome permeates understanding the origin of life and the incredible biodiversity forward current biotechnologies. However, research on the genetics of education have shown that high school students do not understand this concept neither related to the required curriculum content. At the same time, students have distorted ideas about the functionality of the genetic material relating, whenever possible, the characters of fiction, as extraordinary and supernatural profiles; which makes it even more distant between the knowledge of school-popular-scientific triad on this topic. The potential for discussions that the concept of genome features in the teaching of biology, this article presents and proposes a teaching strategy using super adventure genre films combining the concept of genome health topics in high school. For this research, workshops were held dialogic with 115 students from four public schools located in underprivileged areas of the State of Rio de Janeiro, using superheroes of Marvel Comics movies. The pre conceptions and didactic post-workshops were analyzed in the light of the Theory of Meaningful Learning and revealed the relevance of the activity with regard to the approach of knowledge related to the concept of genome and the relevance of the issue before the compulsory school curriculum.
\end{abstract}

Keywords: genetics education; health; movie superheroes; high school.

1 FIOCRUZ - Laboratório de Inovações em Terapias, Ensino e Bioprodutos.

2 Doutora em Biologia Celular e Molecular e docente no Programa Stricto Sensu em Ensino em Biociências e Saúde - IOC - Fundação Oswaldo Cruz - FIOCRUZ, Professora no Programa Stricto Sensu em Ensino em Ciências da Saúde e do Meio Ambiente - UNIFOA - Centro Universitário de Volta Redonda - RJ e no Departamento de Ensino de Ciências Biológicas na Universidade do Estado do Rio de Janeiro - UERJ. 


\section{INTRODUÇÃO}

Nas palavras de Fourez (1994), “A educação representa o patrimônio científico-cultural da humanidade que é transmitido a cada geração", e que pode ser entendida como uma forma de tornar a sociedade menos alheia ao desenvolvimento científico e tecnológico. Hobsbawn (1995) complementa que negligenciar o acesso à educação e ao desenvolvimento científico é tornar a sociedade cada vez mais submissa a uma condição de subjugação cultural e econômica.

Ao se discutir desenvolvimento científico, os avanços no campo da genética são, sem dúvida, os que encontram maior espaço desde a segunda metade do século XX (THOMPSON \& THOMPSON, 1991; RABINOW, 2002; LEITE, 2007; SCHNEIDER et al., 2011). No entanto, pesquisadores da área de ensino têm evidenciado que os conteúdos de genética são indicados pelos estudantes de diferentes países e níveis de escolaridade como os mais difíceis de serem compreendidos (BAHAR, JOHSTONE E HANSELL, 1999; TEKKA YA, ÖZKAN E SUNGUR, 2001; ANDO et al., 2008). Ao passo que a compreensão da funcionalidade do genoma é pré-requisito ao entendimento de conceitos vinculados à vida, como mutação, evolução, biodiversidade, saúde e biotecnologia, todos inseridos no currículo estabelecido para os últimos anos de escolaridade básica no Brasil (BRASIL, 2002).

O Currículo Mínimo é um documento deliberado pela Secretaria de Estado de Educação (SEEDUC) do Rio de Janeiro e nele constam os conteúdos a serem trabalhados em sala de aula, em cada ano escolar e disciplina. Esse documento não limita os conteúdos que devem ser ensinados pelos professores da Educação Básica, mas destacam os conteúdos essenciais, os quais devem estar, obrigatoriamente, no planejamento do curso. Desta forma, os documentos permitem a inserção de novos temas pertinentes aos conteúdos ditos "mínimos” ao processo de ensino e aprendizagem.

Em se tratando da Educação Básica, a disciplina Biologia apresenta conceitos afins ao tema Genoma ao longo das três séries do Ensino Médio Regular. Conceitos de Citologia e Evolução se encontram elencados no Currículo Mínimo determinado para o $1^{\circ}$ Ano, assim como Biodiversidade e Saúde, para o $2^{\circ}$ Ano e Genética e Biotecnologia, para o $3^{\circ}$ Ano (CURRÍCULO MÍNIMO, 2015). Ou seja, no decorrer dos três últimos anos de formação básica, no Brasil, a aprendizagem do conceito de genoma mostra-se necessário, podendo ser inferido como central à compreensão da vida e de sua manutenção (GAGLIARDI, 1986).

Pesquisa recente realizada pelas autoras com 197 alunos do Ensino Médio de quatro escolas públicas no Rio de Janeiro mostra que $90 \%$ dos estudantes pesquisados desconhecem o conceito de "Genoma" e, consequentemente as interfaces que apresenta com os temas supracitados no Currículo Mínimo (NASCIMENTO e MEIRELLES, 2014). Como consequência, têm sido propostas algumas alternativas visando facilitar a aprendizagem dos alunos com relação a conceitos científicos abstratos, como é o caso dos conceitos em genética (KRASILCHIK, 2004; JUSTINA e FERLA, 2006). Uma das propostas é a utilização de filmes em sala de aula (NAPOLITANO, 2013). Napolitano (2013, p.12) enfatiza que "os filmes sempre têm alguma possibilidade de trabalho escolar" e Almeida (2001 apud CARVALHO, 2007) acrescenta que a projeção de filmes pode estimular debates e reflexões críticas dos estudantes acerca de fatos e problemas históricos, culturais, sociais, econômicos e políticos da sociedade.

Em paralelo, Nildo Viana (2011) afirma que "os super-heróis são produtos históricos e sociais assim como qualquer outra produção cultural”. Viana acredita que os super-heróis são capazes não só de divertir crianças e adolescentes, mas orientar as projeções de papéis sociais, enriquecer culturalmente e auxiliar a capacidade intelectual e as ansiedades de uma sociedade marcada pela tecnologia e as injustiças (VIANA, 2011). E, nesse caso, pode-se inferir que mídias em geral podem desempenhar um papel crucial na disseminação de termos científicos e na formação de opiniões, atingindo a todos, inclusive aqueles que estão no ambiente escolar (NOGUEIRA, 2001). E se as mídias disseminam, ainda que de forma artística e descomprometida com a ciência, conceitos científicos, suas contribuições como recurso didático também têm se mostrado influentes, apresentando resultados promissores no ensino de biociências. 


\section{PERCURSO METODOLÓGICO}

Esta pesquisa está vinculada ao Plano Brasil sem Miséria, que visa dentre outros aspectos ligados à pobreza, maior acesso da população carente a bens, serviços e oportunidades, inclusive, educacionais (BRASIL, 2014).

Portanto, a escolha da região geográfica e socioeconômica da pesquisa foi auxiliada por dados obtidos pelo Instituto Brasileiro de Geografia e Estatística (IBGE, Censo 2010) com critérios como: elevado índice de pobreza e desigualdade no âmbito da educação e da saúde e pelo Índice de Desenvolvimento da Educação Brasileira (IDEB) em 2013, ano em que foi iniciada a pesquisa. Os resultados do IDEB orientaram a escolha por escolas com resultados inferiores ao esperado.

Na perspectiva de que o cinema exerce primazia psicológica, sociocultural, comunicativa e universal (WORTH, 1981), a primeira etapa desta pesquisa correspondeu à identificação de conhecimentos prévios de discentes sobre o tema Genoma e preferências fílmicas. A segunda etapa, a uma série de oficinas didáticas em que foram utilizados filmes de super-heróis com ênfase no processo de ensino e aprendizagem do tema.

As oficinas foram organizadas em três blocos temáticos, no entanto, este artigo tem como objetivo apresentar e propor a estratégia didática utilizada apenas no bloco temático intitulado "Genoma e Saúde”. Os materiais utilizados neste bloco temático foram: recortes de cenas, reportagens sobre saúde e descobertas científicas na área de genética, canetinhas coloridas, cola e tesoura.

A pesquisa foi aprovada pelo Comitê de Ética (Parecer 371.703) em agosto de 2013. Com a aprovação, o Termo de Consentimento Livre e Esclarecido (TCLE) foi entregue aos alunos e responsáveis antes do início das atividades de coleta de dados. Questionários e entrevistas foram utilizados como instrumentos de coleta de dados de discentes do Ensino Médio durante três anos (2013 a 2015). O questionário foi utilizado em turmas de $1^{\circ}$ e $3^{\circ}$ Ano do Ensino Médio e buscou identificar conhecimentos prévios dos alunos sobre genoma e temas afins, bem como as preferências por determinados gêneros fílmicos, a frequência com que assistiam na escola e o objetivo que os levava assistir. Os resultados obtidos através desse instrumento de coleta foram essenciais à elaboração da segunda etapa da pesquisa e se encontram publicados (NASCIMENTO e MEIRELLES, 2014).

\section{RESULTADOS E DISCUSSÃO}

A pesquisa foi desenvolvida em quatro escolas públicas da rede estadual do Rio de Janeiro, sendo a primeira etapa realizada em 2013 (coleta de dados) e a segunda etapa (oficinas didáticas), realizada nos meses de agosto a outubro de 2014. Todas as quatro escolas se encontravam localizadas na Região Metropolitana do Estado do Rio de Janeiro, nos município de Duque de Caxias, Rio de Janeiro e São Gonçalo, em bairros de classe baixa com população considerada carente, segundo os índices do IBGE.

Por se tratar de uma pesquisa qualitativa, oficinas didáticas foram elaboradas na perspectiva do diálogo e da integração de conteúdos, de maneira crítica e reflexiva (ZABALZA, 2004) em uma turma de $2^{\circ}$ Ano do Ensino Médio de cada uma das quatro escolas pesquisadas.

Os alunos que inicialmente participaram da coleta de dados e porventura, em 2014, estavam matriculados em diferentes turmas foram convidados a participar das oficinas, assim como outros que não participaram da coleta de dados em 2013, mas que agora pertenciam ao grupo de alunos participantes. Portanto, as oficinas didáticas realizadas em 2014 é uma continuidade da pesquisa iniciada em 2013, com o mesmo grupo de alunos (acrescido de cinco alunos que não faziam parte do grupo inicial) ao longo de sua formação no Ensino Médio. Dos 116 alunos que participaram da pesquisa em 2013, seis não mais se encontravam matriculados nas escolas e cinco foram incluídos na pesquisa, totalizando 115 participantes das oficinas, em 2014. No total de alunos par- 
ticipantes, dezenove eram maiores de 18 anos e assinaram prontamente o TCLE. Com exceção destes, todos os demais tiveram o consentimento dos responsáveis para que seus dados fossem validados.

As oficinas didáticas foram organizadas em três blocos temáticos: 1) Genoma e Saúde, 2) Genoma e Biociências e 3) Genoma e Biotecnologia. Cada bloco temático teve a duração de 200 minutos, ou seja, quatro tempos de aula por semana, sendo dois tempos de aula seguidos em dias distintos.

Os filmes utilizados nas oficinas foram: Quarteto Fantástico (2005), O Incrível Hulk (2008), X-Men: Primeira Classe (2011) e O Espetacular Homem Aranha (2012). Foram realizados recortes de cenas específicas, que apresentavam ênfase ou evidências da elação "genoma - saúde - ciência”.

A atividade consistiu em um diálogo inicial com a turma, sendo levantadas algumas características marcantes dos personagens destacados nos filmes, seguidos da leitura da sinopse em PowerPoint. As cenas foram pré-selecionadas de acordo com o potencial a ser explorado no campo da saúde em interfaces com o Currículo Mínimo, como, por exemplo, efeito de radiações sobre o genoma, drogas, adrenalina, contaminação de alimentos, acidentes com animais, síndromes, entre outras. Como atividade prática, foi proposto aos alunos, em grupos de quatro ou cinco componentes, escolher uma ou duas cenas exibidas, relacioná-la(s) a alguma(s) reportagem (ns) e figuras entregue(s) inicialmente pela pesquisadora, assim como alguns conteúdos estudados em Biologia e construir um panfleto explicativo de saúde. Cada cena foi exibida a turma duas vezes e debatida entre os grupos.

Os panfletos construídos, bem como a organização das ideias que fizeram parte da estruturação dos mesmos foram expostos à turma por cada grupo. Cada grupo teve 20 minutos para a construção do panfleto e 10 minutos para a apresentação. Após a apresentação, em slide, foram mostrados conteúdos do Currículo Mínimo de Biologia do $1^{\circ}$ e do $2^{\circ}$ Ano do Ensino Médio. O objetivo dessa exposição de conteúdos do Currículo Mínimo foi uma tentativa de aproximar as cenas exibidas e o trabalho realizado por eles através dos panfletos aos conteúdos escolares designados para o ano letivo anterior e para o ano letivo vigente pela Secretaria de Educação. Desta forma, seria possível enfatizar a importância daqueles conhecimentos, rever conceitos outrora estudados e introduzir novos conceitos pertinentes àquele ano letivo, aproximando saberes científicos, escolares e populares sobre o genoma. Exemplos da utilização de filmes de ficção científica no ensino formal são encontrados em literaturas que datam de 1973 corroborando com resultados atuais de que os mesmos podem servir de construto do conhecimento científico (GOMES-MALUF e SOUZA, 2008). Na fala de Gomes-Maluf e Souza (2008), a ficção não é uma "profecia" da Ciência, mas se impregna de elementos da realidade e da produção da Ciência para se fazer ficcional e real perante a opinião pública. Libâneo (1994) complementa que aquilo que o estudante conhece, depende da sua realidade e muitas são as situações, no contexto de ensino, em que os estudantes não se apropriam dos conceitos pelo fato de não estarem relacionados à sua vivência ou ainda por desconhecerem a relevância para sua vida. Quando o aluno recebe informações de acordo com suas experiências e capacidade mental, o novo conhecimento adquire significados para o aprendiz e o conhecimento prévio fica mais rico, mais diferenciado, mais elaborado e adquire mais estabilidade, caracterizando a aprendizagem significativa (MOREIRA e MASINI, 1982; MOREIRA, 1999).

Para facilitar a visualização do recorte das cenas e a prática docente, o Quadro 1 mostrado abaixo, apresenta as cenas, o tempo de duração das mesmas e o conteúdo abordado. Os conteúdos afins que constam no Currículo Mínimo de Biologia para o ano letivo 2015 também foram inseridos neste quadro. 


\section{Quadro 1 - Filmes, cenas e conceitos trabalhados na Oficina Didática intitulada “Genoma e Saúde”.}

\begin{tabular}{|c|c|}
\hline$X-$ Men: Primeira Classe (2011) & O Incrível Hulk (2008) \\
\hline $\begin{array}{l}\text { Cena 1: 4'26' a 9'23" - Mevino (Erik) revela sua mulação genética } \\
\text { após siluação de esiresse e angústia. } \\
\text { Cena 2: } 10^{\prime} 36^{\prime \prime} \text { a } 11^{\prime} 15^{\prime \prime} \text { - Helerocromia. } \\
\text { Cena 3: } 1 \text { b 18' } 36^{\prime \prime} \text { a 1b 18' } 53^{\prime \prime} \text { - Pesquisa mosira a estrutura celular } \\
\text { de uma personagem mulante e comenta sobre envelbecimento } \\
\text { celular. }\end{array}$ & $\begin{array}{l}\text { Cena 1: } 8^{\prime} 00^{\prime \prime} \text { a } 8^{\prime} 45^{\prime \prime} / 13^{\prime} 00^{\prime \prime} \text { a } 13^{\prime} 15^{\prime \prime} \text { - Homem morre após } \\
\text { ingerir bebida conlaminada por sangue de Hulk. } \\
\text { Cena 2: } 18^{\prime} 07^{\prime \prime} \text { a } 25^{\prime} 57^{\prime \prime} \text { - Transformação de Hulk devido a aumento } \\
\text { de batimenlos cardiacos. } \\
\text { Cena 3: } 1 \mathrm{~b} 03^{\prime} 17^{\prime \prime} \text { a } 1 \mathrm{~b} 03^{\prime} 53^{\prime \prime} \text { - Sintomas de Hulk pós- } \\
\text { transformaçâo. }\end{array}$ \\
\hline \multicolumn{2}{|c|}{$\begin{array}{l}\text { Resumo do Currículo Mínimo de Biologia para o Ensino Médio da Rede Pública Estadual-2015 } \\
\text { (http://www.conexaoprofessor.rj.gov.br/curriculo_identificacao.asp) }\end{array}$} \\
\hline \multicolumn{2}{|c|}{ 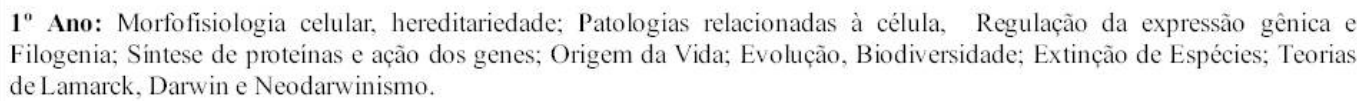 } \\
\hline \multirow{2}{*}{\multicolumn{2}{|c|}{$\begin{array}{l}2^{\circ} \text { Ano: Diversidade celular; Funcionalidade orgânica e hormônios; Funções vitais; Metabolismo energético; Fisiologia } \\
\text { produção de hormônios; Segurança em saúde coletiva; Energia; Adaptação; Doenças e Promoção da Saúde (uso de } \\
\text { medicamentos, exposição a drogas, herança genética...); Doenças infectocontagiosas, hereditárias, congênitas, DSTs } \\
\text { aquelas provocadas portoxinas ambientais. } \\
3^{\circ} \text { Ano: Projetos genomas e sua importância para o homem e o ambiente; Ética na utilização de informaçôes genéticas na } \\
\text { promoção da saúde humana; Humanidade e Ambiente; Ação de agentes mutagênicos no ambiente; Biotecnologia; Técnicas } \\
\text { moleculares de engenharia genética. }\end{array}$}} \\
\hline & \\
\hline Quarteto Fantástico (2005) & O Espetacular Homem-Aranha (2012) \\
\hline $\begin{array}{l}\text { Cena 1:1'30" a } 2 \text { ' } 45^{\prime \prime} \text { - Pesquisas evidenciam que a radiaçâo } \\
\text { cósmica pode alterar o genoma bumano. }\end{array}$ & $\begin{array}{l}\text { Cena 1: } 20^{\prime} 45^{\prime \prime} \text { a } 24^{\prime} 45^{\prime \prime} \text { - Piller Parker é picado por uma aranba } \\
\text { mulante no laboratório de pesquisa. }\end{array}$ \\
\hline $\begin{array}{l}\text { Cena 2: } 16^{\prime} 39^{\prime \prime} \text { a } 30^{\prime} 50^{\prime \prime} \text {-Primeiras manifestaçôes mulantes dos } \\
\text { personagens. }\end{array}$ & $\begin{array}{l}\text { Cena 2: } 1 \mathrm{~b} 25 \text { " } 45 \text { " - Pesquisador fala que o objetivo dos cruzamentos } \\
\text { genéticos não é mais curar doenças. }\end{array}$ \\
\hline $\begin{array}{l}\text { Cena } 3: 44^{\prime} 10^{\prime \prime} \text { a } 57^{\prime} 14^{\prime \prime} / 1 \mathrm{~b} 122^{\prime} 31^{\prime \prime} \text { a } 1 \mathrm{~b} \text { 17'15" - Tempo de } \\
\text { exposição à radiaçâo pode causar danos irreversiveis. }\end{array}$ & $\begin{array}{l}\text { Cena 3: } 1 \mathrm{~b} 41^{\prime} 30^{\prime \prime} \text { a } 1 \mathrm{~b} 55^{\prime} 50^{\prime \prime} \text { - Agente mulagênico aéreo é lançado } \\
\text { na cidade e antidoto contra mulação anula a ação das bioloxinas. }\end{array}$ \\
\hline
\end{tabular}

Fonte: dos autores.

Após a exibição da cena pré-selecionada, alguns conceitos científicos atrelados ao Currículo Mínimo foram ressaltados e a participação dos alunos, com seus conhecimentos prévios, valorizada. Como exemplo citamos o recorte das cenas 1,2 e 3 de " $X$-Men Primeira Classe" que foram utilizadas visando à abordagem dos conceitos: genes e o comportamento humano. O debate foi conectado à cena 2 do filme "O Incrível Hulk", o qual aborda o aumento de batimentos cardíacos do protagonista após situação de estresse. Conteúdos como produção hormonal e expressão gênica foram enfatizados (conteúdos do $2^{\circ}$ Ano do Ensino Médio, de acordo com o currículo). A produção e a ação de hormônios animais foram explicadas e relacionadas às cenas, além de relatos verídicos sobre comportamentos humanos sob a ação dos genes (MURAKAMI, 2008).

As cenas nomeadas como 2 e 3 de " $X$-Men" foram debatidas paralelamente visando potencializar conhecimentos sobre a estrutura celular, sobretudo o núcleo eucariota e as alterações que podem ocorrer no material genético sob a ação de agentes mutagênicos. Dentre os agentes mutagênicos, estão certos tipos de radiação, drogas, álcool, alimentos industrializados e o fator hereditariedade (conteúdos presentes no currículo das três séries do Ensino Médio). Alguns tipos de mutações genéticas foram abordados e o tema "preconceito" também foi discutido.

Através do debate entre os alunos e a pesquisadora, foi possível chegar a conclusões interessantes sobre prevenção e cuidados com a saúde e que pequenas modificações do DNA nem sempre conferem um defeito, uma anomalia, mas também pode evidenciar adaptação e até mesmo diversidade dentro de uma espécie.

A cena 1 do filme "Quarteto Fantástico" foi fundamental para ratificar que determinados agentes mutagênicos podem causar sérios danos ao material genético (OKUNO, 2007). A cena 2 desse mesmo filme reforça o conceito de que o tempo de exposição a determinado agente mutagênico, como a quantidade de radiação a que um indivíduo é exposto, pode fazer com que as consequências celulares sejam permanentes (Op. Cit, 2007). A 
cena 3 permite a compreensão de que, embora vários indivíduos de uma mesma espécie sejam expostos a um mesmo agente mutagênico, as expressões genéticas (manifestações do gene) podem ser diferentes (JUNQUEIRA e CARNEIRO, 2013; OKUNO, 2007).

No contexto das radiações ionizantes ou não ionizantes, as drogas ilícitas, assim como alguns medicamentos utilizados indevidamente, podem ser incluídos como substâncias mutagênicas (BARALE et al., 1998; OKUNO, 2007). Substâncias mutagênicas podem causar diversas mudanças no material genético, inclusive câncer (MINISTÉRIO DA SAÚDE, 2002). Os efeitos das drogas como maconha, heroína, cocaína, ecstasy e outras podem ser debatidos com os alunos utilizando a cena 3 do filme “O Incrível Hulk”, embora os sintomas do personagem não sejam de overdose por drogas, podem ser assemelhados a overdose por adrenalina, consequências de uma mutação.

A cena 1 de "O Incrível Hulk” e as outras três cenas recortadas do filme "O Espetacular Homem-Aranha” podem enredar uma boa discussão com os alunos sobre fontes de contaminação alimentar por bactérias, protozoários ou animais. Nesse debate, devem ser incluídos métodos profiláticos e tratamentos eficazes em caso de infecção. A riqueza de conteúdos que podem adentrar os debates com a turma podem abarcar ainda os temas vacinação e biotecnologia, presentes no Currículo Mínimo.

Como atividade prática, os alunos deveriam, em grupo, escolher as cenas, o tema e as reportagens que mais se adequavam para explicar, no panfleto, os riscos e cuidados necessários para a manutenção da saúde. Após a construção dos panfletos, os grupos deveriam apresentá-lo à turma e discutir a razão da escolha pelo tema e as dificuldades encontradas na construção do panfleto.

A Tabela 1 mostra quatro exemplos de capa dos panfletos construídos nas quatro escolas participantes da pesquisa. O panfleto cujo interior apresenta-se em destaque mostra a conexão das cenas apresentadas com o conteúdo escolhido pelo grupo: Radiação. O grupo relacionou figuras como a da bomba atômica e do acidente nuclear em Fukushima aos efeitos da radiação mostradas nos filmes $X$-Men: Primeira Classe e Quarteto Fantástico. Os efeitos nocivos da radiação solar e a importância da prevenção e os cuidados com a saúde ficaram evidentes no panfleto, como pode ser visto na Tabela 1.

\section{Tabela 1 - Panfletos de saúde construídos por alunos durante} oficinas com o uso de filmes de Ficção Científica.

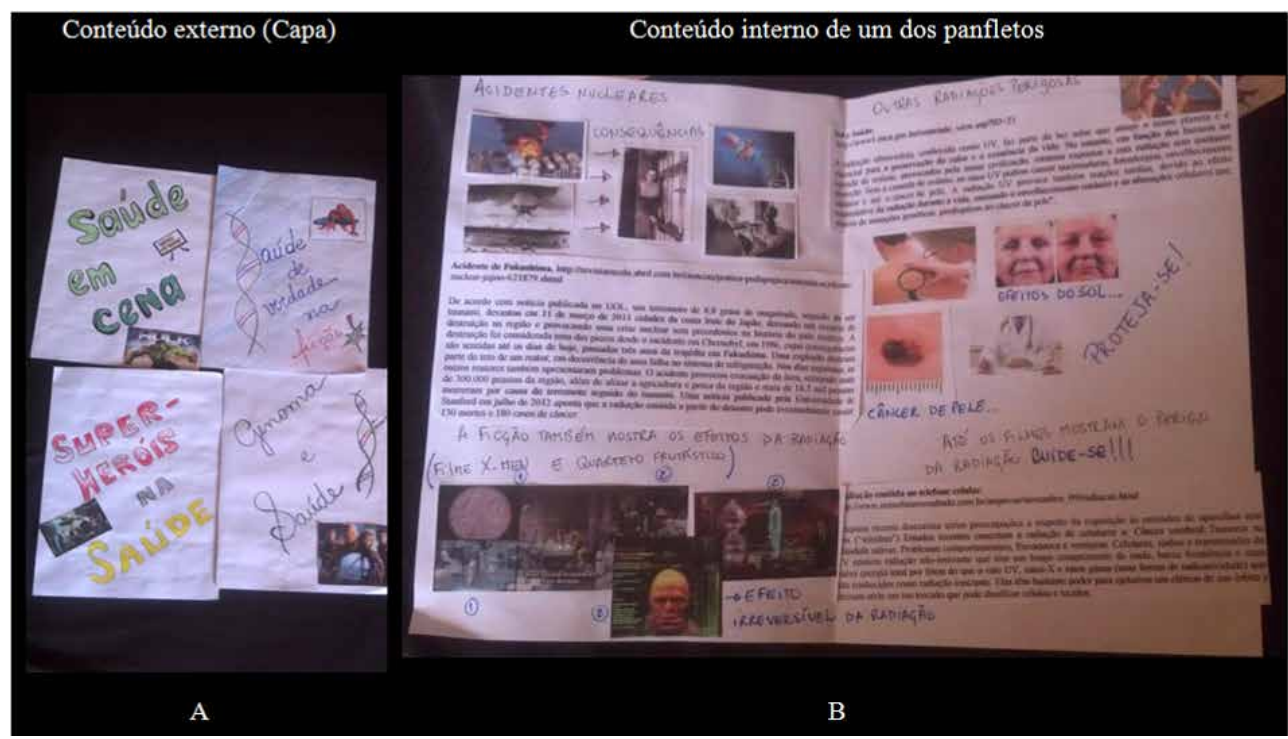

A. Capa de alguns panfletos construídos. B. Exemplo de conteúdo interno do panfleto abordando o perigo das radiações nuclear e solar sobre o material genético em conexão com o filme Quarteto Fantástico. Fonte: dos autores. 
Os principais comentários destacados a partir das falas dos alunos foram de que, apesar de conhecerem os super-heróis mostrados em cada cena, nunca tinham reparado a relação de uma cena fílmica com o que estudavam em Biologia, na escola. Comentaram que sempre pensaram nas estórias de super-heróis com grande afeição, mas apenas como fantasia plena.

Em pesquisas sobre a relação dos super-heróis com a cultura e a sociedade, Viana e Reblin (2011) comentam que a riqueza simbólica das tramas apresentadas nos filmes de superaventura pode desencadear uma série de representações singulares. Essas representações podem enriquecer valores culturais e ajudar os professores a trabalhar, inclusive, as emoções humanas, apresentando grande potencial em diferentes disciplinas escolares (VIANA e REBLIN, 2011).

Napolitano (2013) enfatiza que:

“Trabalhar com o cinema em sala de aula é ajudar a escola a reencontrar a cultura ao mesmo tempo cotidiana e elevada, pois o cinema é o campo no qual a estética, o lazer, a ideologia e os valores sociais mais amplos são sintetizados numa mesma obra de arte” (NAPOLITANO, 2013, p.11).

Desta forma, o primeiro desafio proferido pelos alunos foi tentar encontrar fenômenos biológicos ou fatos reais no filme, já que nunca antes tinham pensado haver, num filme de ficção científica, veracidade científica. O segundo maior desafio relatado pelos alunos foi escolher uma ou duas cenas exibidas, organizá-las em um pequeno panfleto e resumir, de forma educativa e simples, o tanto de conteúdos que conseguiram conectar ao currículo e que achavam importantes.

Diante desse resultado, importa ressaltar que, ao final do ano 2013, na primeira etapa desta pesquisa, 90\% desse grupo de alunos mostraram, através de questionário e entrevista, não saber definir “Genoma” tão pouco contextualizá-lo com assuntos pertinentes ao Currículo Mínimo de Biologia para a série em que estavam matriculados (NASCIMENTO e MEIRELLES, 2014). Após a atividade, foi percebida uma aproximação de saberes e a ressignificação não só dos conceitos científicos que antes poderiam estar associados exclusivamente à ficção, mas uma nova forma de ver e compreender os conteúdos escolares obrigatórios. Nesse sentido, David Ausubel (2000 apud Moreira, 2011) define a aprendizagem significativa como àquela que atribui significados que ancorem de forma substantiva (não literal) e não arbitrária, os novos conhecimentos aos conhecimentos prévios do indivíduo. Logo, a aprendizagem significativa tem por base a ideologia construtivista, concebendo a ideia de que o indivíduo não é passivo aos estímulos externos, afinal, sempre busca uma forma de interagir com eles para construir e organizar o seu próprio conhecimento de forma cada vez mais elaborada (LA TAILLE et al., 1992). Essa ideologia tem como base que aprender, assim como ensinar, é algo que diz respeito a construir um novo conhecimento, descobrindo uma nova forma de percepção para um dado fenômeno.

A aproximação de conceitos científicos e escolares é algo almejado no ensino das biociências e intrínseco à aprendizagem significativa, uma vez que, é pela ancoragem dos novos conhecimentos às ideias prévias que os indivíduos tornam-se capazes de organizar, de forma hierarquizada, o conhecimento, trazendo significados permanentes à sua estrutura cognitiva (AUSUBEL, 2000).

Um instrumento que pode evidenciar a aprendizagem significativa é o Mapa Conceitual, permitindo que, individualmente, os alunos estabeleçam as relações entre os diferentes conceitos estudados (MOREIRA, 2011). Para verificar as possíveis conexões estabelecidas pelos alunos após as atividades na oficina, foi solicitada a construção de um Mapa Conceitual individual. Os mapas construídos pelos alunos puderam corroborar com a Teoria da Aprendizagem Significativa. Por esse fato, na Figura 1 se encontra um exemplo de Mapa Conceitual feito por um aluno. 
Figura 1. Exemplo de Mapa Conceitual feito por um aluno após oficinas didáticas com filmes.

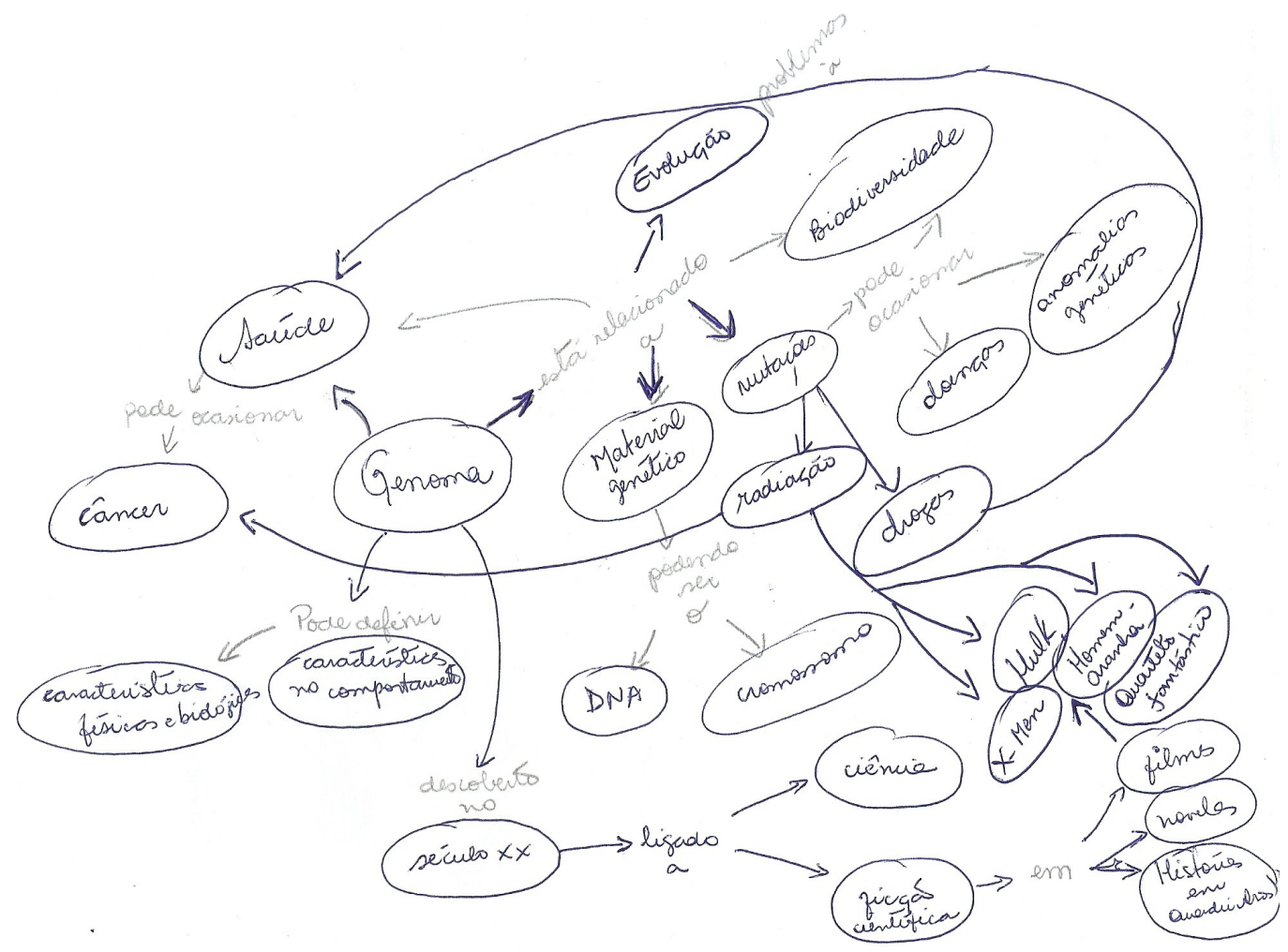

Fonte: dos autores.

Pode-se inferir que a atividade proposta nesta oficina facilitou a conexão de conteúdos escolares que constam no Currículo Mínimo através da curiosidade ou do interesse dos discentes em buscar, nas cenas dos filmes de fiç̧ão exibidos, algo que pudesse estar relacionado a ciência. E apesar da fiç̧ão científica não ter o objetivo de ensinar Ciências, ficou claro que é possível, ver conhecimento científico, e não apenas especulação científica, em obras de ficção científica do gênero superaventura (GRESH E WEINBERG, 2005).

Não é à toa que as ciências sociais e humanas têm se voltado ao estudo das influências midiáticas no comportamento e aprendizado humano. Viana e Reblin (2011) enfatizam que a sociedade apresentada nas narrativas da ficção não é apenas aquela em que vivemos, mas a que tememos, almejamos ou sonhamos, por isso, muitos se apropriam dela. No mundo dos super-heróis, os superpoderes são frutos de um processo de evolução da espécie que, pelos passos largos que a ciência tem dado rumo ao genoma e à biotecnologia, torna-se um "mito moderno" (REBLIN 2008 apud VIANA e REBLIN, 2011) e um interessante campo de investigação no ensino das biociências.

Myriam Krasilchick (2004) acrescenta que o desafio de integrar novos temas aos conteúdos tradicionais do ensino é imprescindível a uma atuação docente consistente e coerente com as perspectivas do ensino de ciências para o século XXI. Esta aproximação de saberes contribuirá no sentido de minimizar a alienação da sociedade diante das descobertas científicas de seu tempo e permitirá que muitos desses conhecimentos científicos atuais ultrapassem os muros das escolas gerando melhoria da qualidade de vida dos alunos. Portanto, com esses desafios no ensino de genética, a educação brasileira precisa adequar-se a esta realidade, aproximando a escola desses novos conceitos (INOCÊNCIO et al., 2001). 


\section{REFERÊNCIAS BIBLIOGRÁFICAS}

ANDO, N.; SAITO, Y.; TAKEMURA, K.; TAKADA, F.; IWAMITSU, Y. Journal compilation- clin genet printed in Singapore, pp. 75-81, 2008.

AUSUBEL, D. P. The acquisition and retention of knowledge: a cognitive view. Dordrecht: Kluwer Academic Publishers, 2000.

BAHAR, M.; JONSTONE, A. H. E HANSELL, M. H. Revisiting Learning Difficulties in Biology. Journal of Biological Education, 33, p. 84-86, 1999.

BARALE, R.; CHELOTTI, L.; DAVINI, T.; DELRY, S.; ANDREASSI, M. G.; BALLARDIN, M.; BULLERI, M.; HE, J.; BALDACCI, S.; DI PEDE, F.; GEMIGNANI, F. \& LANDI, S. Sister chromatid exchange and micronucleus frequency in human lymphocytes of 1,650 subjects in an Italian population: II. Contribution of sex, age and lifestyle. Environmental Molecular Mutagenesis, 31:228-242, 1998.

BRASIL. Ministério do Desenvolvimento Social e Combate a Fome. O Brasil sem Miséria. Organizadores: Tereza Campello, Tiago Falcão, Patrícia Vieira da Costa. Brasília: MDS, 2014.

PCN+ Ensino Médio: orientações educacionais complementares aos Parâmetros Curriculares Nacionais. Vol. Ciências da natureza, matemática e suas tecnologias. Brasília: MEC. 2002.

CARVALHO, R. I. B. Universidade midiatizada: o uso da televisão e do cinema na educação superior. Brasília: Senac-DF, 2007.

CURRÍCULO MÍNIMO. Secretaria de Estado de Educação, 2015. Disponível em: < http://www.ri.gov.br/web/ seeduc/exibeconteudo?article-id=759820>

FOUREZ, G. Alphabétisation scientifique et technique. Bruxelles, Belgium, 1994.

GAGLIARDI, R. Los Conceptos Estructurantes em El Aprendizage por Investigación. Ensenãnza de Las Ciencias, pp.30-35, 1986.

GOMES-MALUF, M. C.; SOUZA, A. R. A Fiç̧ão Científica e o Ensino de Ciências: o imaginário como formador do real e do racional. Ciência \& Educação, Bauru, v.14, n.2, 2008.

GRESH, L.; WEINBERG, R. A Ciência dos Super-heróis. Rio de Janeiro: Ediouro, 2005.

HOBSBAWM, E. A Era dos Extremos. O breve século XX - 1914-1991. São Paulo: Companhia das Letras, 1995.

INOCÊNCIO, M. T.; FAGUNDES, M. G.; OLIVEIRA, M. G. M. G.; GASPARINI, A. T. B.; BARBIERI, M. R.; COVAS D. T. Doenças hereditárias e não-hereditárias - estratégias de ensino e incentivo. In: $\mathbf{4 7}^{\circ}$ Congresso Nacional de Genética. Águas de Lindóia, 2001. Resumos, SBG - Sociedade Brasileira de Genética, 2001. Disponível em: <http://sites.netsite.com.br/sbgteste/PDF/47/1426.pdf> $>$. Acessado em: 23 de março de 2011.

JUSTINA, L. A. D.; FERLA, M. R. A Utilização de Modelos Didáticos no Ensino de Genética - exemplo de representação de compactação do DNA eucarioto. 2006.

JUNQUEIRA, L. C.; CARNEIRO, J. Histologia Básica. Editora Guanabara Koogan, 12º Edição, 2013.

KRASILCHICK, M. Práticas do Ensino de Biologia. São Paulo: EDUSP; Universidade de São Paulo, 4ª Ed, 2004.

LA TAILLE, Y.; OLIVEIRA, M. K.; DANTAS, H. Piaget, Vygotsky, Wallon: teorias psicogenéticas em discussão. O lugar da interação social na concepção de Jean Piaget. 13a ed. São Paulo: Summus, 1992. 
LEITE, M. Promessas do Genoma. São Paulo: Editora UNESP, 2007.

LIBÂNEO, J. C. Didática. Série Formação do professor. Editora Cortez, 33ª impressão, 1994.

MINISTÉRIO DA SAÚDE. Instituto Nacional de Câncer. Coordenação de programas de controle do câncer. O problema do câncer no Brasil. Quarta edição revisada e atualizada. Rio de Janeiro, 2002.

MOREIRA, M. A. Teorias de Aprendizagem. 2.ed. ampliada. São Paulo: EPU, 2011.

. Aprendizagem significativa. Brasília: Editora da UnB, p.129, 1999.

MOREIRA, M. A.; MASINI, E. A. S. Aprendizagem significativa: a teoria de aprendizagem de David Ausubel. São Paulo: Editora Moraes, p.112, 1982.

MURAKAMI, K. Código Divino da Vida: ative seus genes e descubra quem você quer ser. São Paulo: PróLibera Editora, 2008.

NAPOLITANO, M. Como usar o cinema na sala de aula. São Paulo: Contexto, 2013.

NASCIMENTO, J. M. L.; MEIRELLES, R. M. S. O conceito de genoma na perspectiva de discentes do Ensino Médio de escolas localizadas em áreas carentes do Estado do Rio de Janeiro. Revista Ensino, Saúde e Ambiente, v. 7 , n 1, Edição Especial, maio de 2014.

NOGUEIRA, R. P. Higiomania: a obsessão com a saúde na sociedade contemporânea. In:Vasconcelos, E.M. (Org) A saúde nas palavras e nos gestos: reflexões da rede de educação popular e saúde. São Paulo: Editora Hucitec, capítulo 5; p.94-119, 2001.

OKUNO, E. Radiação: efeitos, riscos e benefícios. São Paulo: HARBRA, 2007.

RABINOW, P. Antropologia da razão - ensaios de Paul Rabinow. Rio de janeiro: Relume Dumará, 2002.

SCHNEIDER, E. M.; JUSTINA, L. A. D. ANDRADE, M. B. S.; OLIVEIRA, T. B.; CALDEIRA, A. M. A.; MEGLHIERATTI, F. A. Conceitos de gene: construção histórico-epistemológica e percepções de professores do ensino superior. Investigações em Ensino de Ciências, v.16 (2), p.201-222, 2011.

TEKKA YA, CEREN.; ÖZKAN, ÖZLEM. E SUNGUR, S. Biology concepts perceived as difficult by turkish high school students lise ögrencilerinin zor olarak algiladiklari biyoloji kavramlari. Hacettepe üniversitesi eğitim fakültesi dergisi. V.2, 145-150. 2001.

THOMPSON, M. W.; McINNES, R. R.; WILLARD, H. F. (THOMPSON \& THOMPSON). Genética Médica. 5 ${ }^{\mathrm{a}}$ Ed. Guanabara Koogan, 1991.

VIANA, N.; REBLIN, I. A. Super-Heróis, Cultura e Sociedade: Aproximações multidisciplinares sobre o mundo dos quadrinhos. Aparecida, SP: Idéias \& Letras, 2011.

WORTH, S. The Uses of Film in Education and Communication. In: Larry Gross (ed.). Studying Visual Communication. Philadelphia: University of Pennsylvania Press, 1981.

ZABALZA, M. Diários de aula: um instrumento de pesquisa e desenvolvimento profissional. Porto Alegre: Artmed, 2004. 